\title{
THE THIRD HEART SOUND IN MITRAL REGURGITATION
}

\author{
BY \\ P. G. F. NIXON \\ From the Departments of Thoracic Surgery and Medicine in the General Infirmary at Leeds \\ Received February 22, 1961
}

The origin of the third heart sound or protodiastolic gallop rhythm of mitral regurgitation is not established. It has been thought to lie in the myocardium, in the mitral cusps and chordæ, and in impact of the heart against the chest wall. The sound has been attributed to an increased rate of ventricular filling, to reduced myocardial tone, to active relaxation of the left ventricle, to

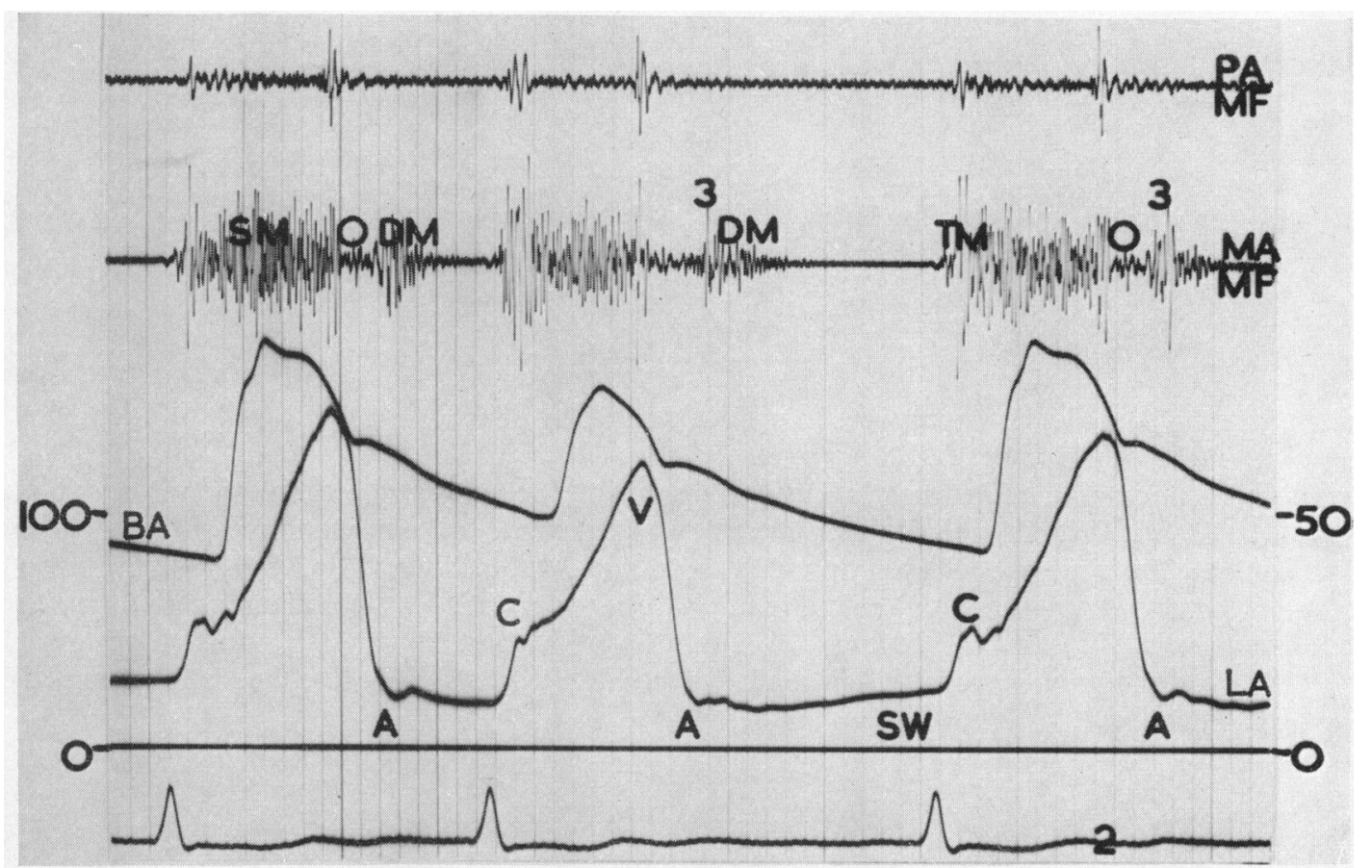

FIG. 1.-Mitral regurgitaion. Pulmonary area medium frequency (PA/MF), and mitral area medium frequency (MA/MF) phonocardiograms, brachial arterial pulse (BA), left atrial pulse (LA), and lead 2 electrocardiogram.*

The mitral phonocardiogram records the pansystolic murmur of mitral regurgitation (SM) and the opening snap (O). The diastolic murmur (DM) has a loud onset. In the second and third complexes there is a third heart sond (3).

$T M=$ tricuspid and mitral valve closure. $C$ and $V=$ left atrial "c" and "v" waves. $A=$ annular ascent point. $\mathrm{SW}=$ stasis wave.

* Where two scales are shown that on the left refers to brachial arterial pressures and that on the right to left atrial pressures. In figures 1-7 time marker lines indicate 0.04 and 0.2 second intervals. 


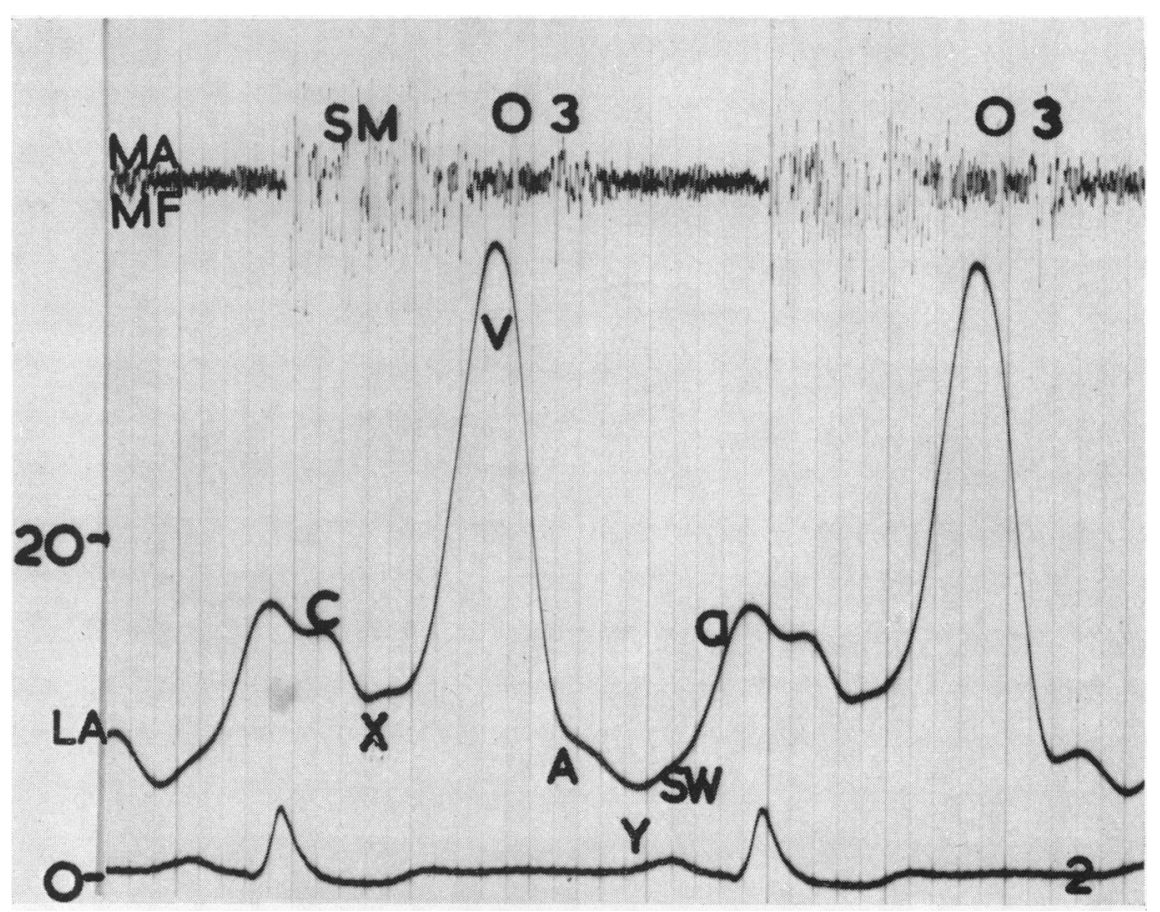

FIG. 2.-Mitral regurgitation. Mitral area medium frequency phonocardiogram (MA/MF), left atrial pressure pulse (LA) and lead 2 electrocardiogram.

The phonocardiogram shows a pansystolic murmur of mitral regurgitation (SM), mitral opening snap (O) and third heart sound (3).

$a, C, V, X, Y=$ left atrial " $a$ " "c" and " $v$ " waves, and " $x$ " and " $y$ " troughs. $\mathrm{A}=$ annular ascent point. $\mathrm{SW}=$ stasis wave.

sudden arrest of ventricular expansion, to sudden stretching of the ventricular wall, to opening and to closing of the mitral valve.

Advances in cardiac catheterization technique during the last decade have made it possible to record heart sounds simultaneously with arterial and left atrial or ventricular pressures in patients with rheumatic heart disease. When the results are studied in the light of Dock's (1959) experimental work it appears likely that the third sound in mitral regurgitation results from tautening of the thickened fibrous part of the mitral valve as the annulus fibrosus ascends and the cusps move towards each other under conditions of left ventricular diastolic hypertension. The theory is examined in this communication.

\section{Material AND Methods}

Patients with chronic rheumatic mitral valvular disease subjected to diagnostic left heart catheterization were selected for this study provided they were free from hypertensive, ischæmic, and aortic valvular disease. None were thought to have tricuspid opening snaps or right ventricular third heart sounds. The final diagnosis of the mitral valve lesion-stenosis, stenosis with regurgitation, or regurgitation-was made from consideration of the clinical and phonocardiographic features of the case, the left atrial indicator-dilution curves and pressure pulses, and from the surgeon's assessment of the valve at operation. Twenty-three disabled patients were studied. Pure mitral stenosis was present in four, mitral stenosis with regurgitation in six, and predominant mitral regurgitation in thirteen. 


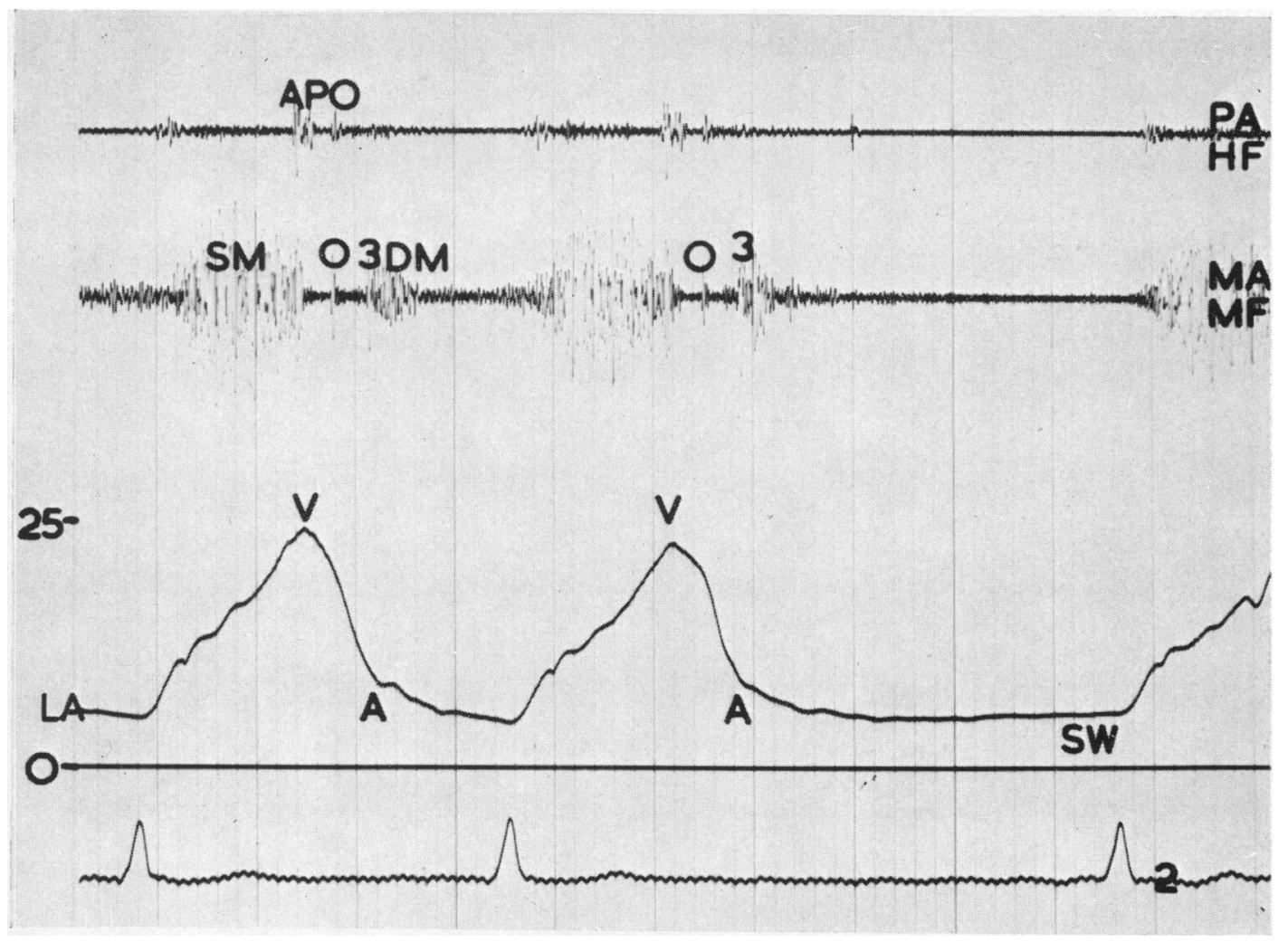

FIG. 3.-Mitral regurgitation. Pulmonary area high frequency (PA/HF) and mitral area medium frequency (MA/MF) phonocardiograms, left atrial pulse (LA) and lead 2 electrocardiogram.

The mitral phonocardiogram shows the pansystolic murmur of mitral regurgitation (SM) and the mitral opening snap (O). The third sound (3) is immediately followed by a loudly beginning diastolic murmur (DM). Diastolic murmur vibrations between $O$ and 3 are small. APO $=$ aortic and pulmonary valve closure and mitral opening snap.

$\mathrm{V}, \mathrm{A}$, and $\mathrm{SW}=$ left atrial "v" wave, annular ascent point, and stasis wave.

The left heart was catheterized through the atrial septum (Ross, 1959; Nixon, 1960). High or medium frequency phonocardiograms (Leatham, 1952) in the pulmonary and mitral areas were recorded simultaneously with brachial arterial and left atrial or ventricular pressure pulses and lead II of the electrocardiogram during expiratory pauses. Tracings were recorded photographically at a paper speed of $80 \mathrm{~mm}$. per second. A lens and graticule were used to measure intervals to the nearest $0.1 \mathrm{~mm}$. Time and pressure measurements were averaged for at least ten beats. Atrial and ventricular pressures were obtained with Statham P23Db or P23G transducers through $90 \mathrm{~cm}$. lengths of P.E.50 catheter (Clay-Adams, Inc.). Brachial arterial pressures were obtained through Cournand needles connected to similar transducers by $30 \mathrm{~cm}$. lengths of thick walled inelastic polyethylene tubing (internal diameter $3 \mathrm{~mm}$.). All pressures were measured in $\mathrm{mm}$. $\mathrm{Hg}$ with the patient supine, and with the zero level at the sternal angle. Transmission times from catheter tip and microphone to the camera were compared by bursting a balloon inflated over the end of the catheter and held close to the microphone. Pressure events were delayed 5 milliseconds longer than sound events and this was taken into account in the calculation of results. The experiment showed that the atrial pressure recording system was slightly underdamped and required 9 milliseconds to record an instantaneous fall from full scale deflection to zero pressure.

Aortic valve closure, mitral opening snap and third heart sound "transients" were timed from 


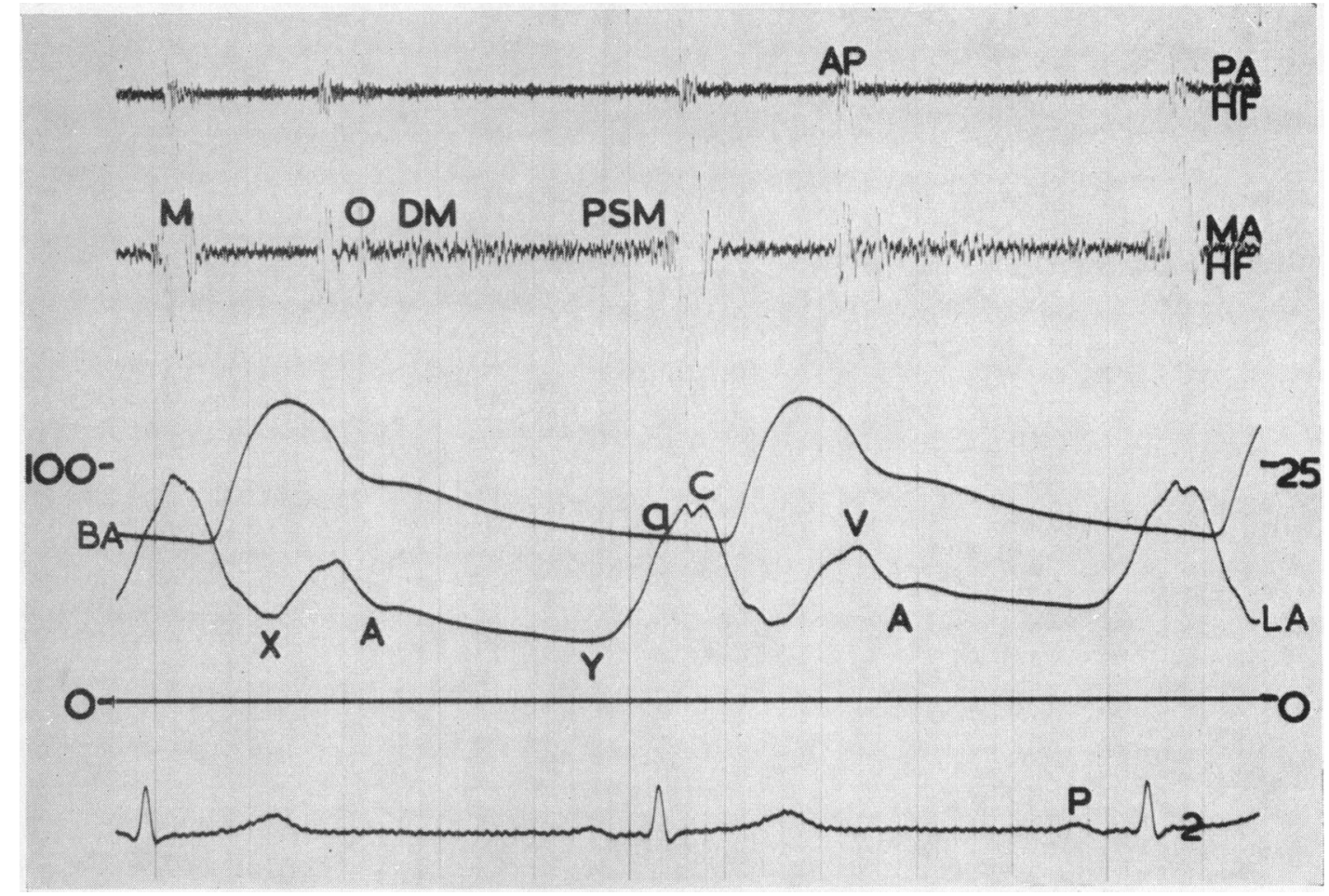

FIG. 4.-Mitral stenosis. Pulmonary area high frequency (PA/HF) and mitral area high frequency (MA/HF) phonocardiograms, brachial arterial pulse (BA), left atrial pulse (LA), and lead 2 electrocardiogram. The mitral diastolic murmur (DM) begins quietly at the opening snap (O) and is accentuated (PSM) at the time of the left atrial " $a$ " wave. $M=$ mitral valve closure. AP=aortic and pulmonary valve closure.

The left atrial pulse shows " $a$ " " $c$ " and " $v$ " waves $(a, C, V)$ and " $x$ " and " $y$ " troughs $(X, Y)$. The down-slope from " $\mathrm{v}$ " to " $\mathrm{y}$ " is interrupted by a notch (A), the annular ascent point, which is followed by a small positive wave, the annular ascent wing.

the onset of their vibrations on the phonocardiogram. They were identified by their relationship to each other and to the pressure pulses. A third sound was considered to be present when short-lived vibrations twice the size of a "loudly-beginning" mitral diastolic murmur occurred close to its onset. This arbitrary decision was made because it is sometimes difficult to decide whether large vibrations indicate a sound or merely form part of a murmur. The "loudly-beginning" diastolic murmur identifies mitral orifices measuring $2.0 \mathrm{~cm}$. or more in patients disabled from mitral regurgitation and mitral fibrillation, and is distinct from the "quietly-beginning" mitral diastolic murmur of severe stenosis with or without regurgitation (Nixon and Wooler, 1960).

The Left Atrial Diastolic Pressure Pulse. In mitral incompetence the left atrial "y" descent usually has three parts (Fig. 1). The first is a decline which extends from the apex of the "v" wave to a point coinciding with the inscription of the opening snap on the phonocardiogram. The second is a rapid fall in pressure from the time of the opening snap to the "annular ascent point," defined by Radner (1957, 1958). This point (A in Fig. 1-6) is marked by an angulation as the pressure decline slows abruptly, or by the beginning of a small positive wave, the "annular ascent wing." The third part of the " $y$ " descent is a more gradual downslope from the annular ascent point or from the apex of the annular ascent wing to the inscription of the " $a$ " wave in sinus rhythm, the " $c$ " wave in atrial fibrillation, or to the positive wave that identifies ventricular stasis (Mackenzie, 1902) during the period of diastasis (Henderson, 1906; Wiggers, 1921); this stasis wave occurs in patients 


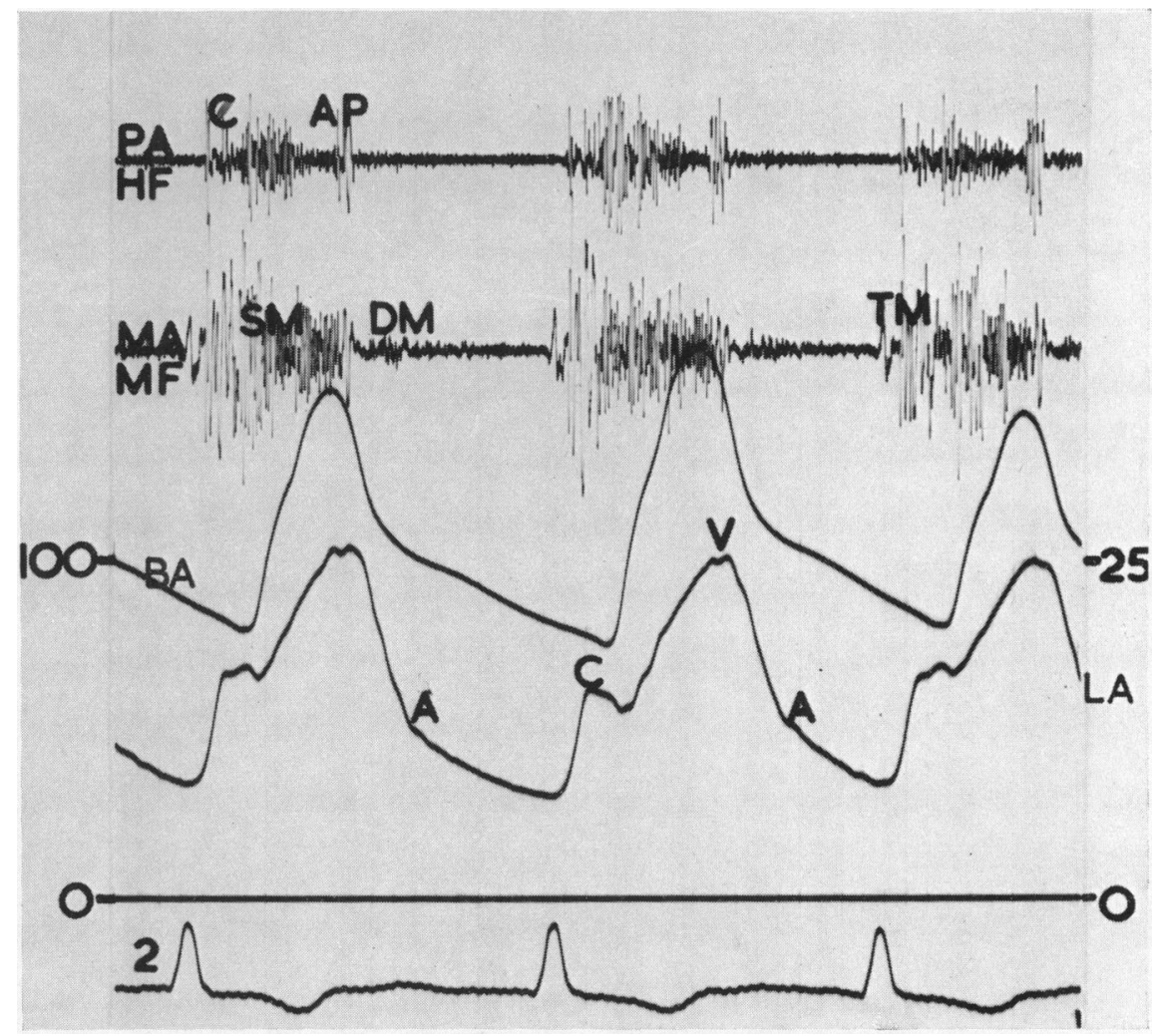

FIG. 5.-Mitral stenosis with regurgitation. Pulmonary area high frequency (PA/HF) and mitral area medium frequency (MA/HF) phonocardiograms, brachial arterial pulse (BA), left atrial pulse (LA) and lead 2 electrocardiogram.

The mitral phonocardiogram shows a pansystolic murmur (SM), no opening snap, and a quietly beginning diastolic murmur (DM). TM=tricuspid and mitral valve closure. $\mathrm{AP}=$ aortic and pulmonary valve closure. $\mathrm{e}=$ pulmonary ejection click.

The left atrial pulse has " $c$ " and " $v$ " waves and the downslope from " $v$ " becomes less rapid at the annular ascent point (A).

disabled from mitral valvular disease when the mitral orifice measures $2.0 \mathrm{~cm}$. or more (Nixon and Wooler, 1961), and is absent in severe stenosis (Braunwald et al., 1955; Morrow et al., 1957).

Time intervals were measured from aortic valve closure to the mitral opening snap and third heart sound, and to the annular ascent point. When left ventricular stasis occurred the interval from aortic closure to the onset of the left atrial stasis wave was determined. Where possible the time between aortic valve closure and the nadir of left ventricular diastolic pressure was measured.

\section{RESULTS}

Heart Rhythm. Sinus rhythm was present in each patient with pure mitral stenosis, and atrial fibrillation in all but three of the remainder.

Surgical Findings. The long diameter of the mitral orifice was examined at operation by Mr. G. H. Wooler and estimated to be 2.2 to $4.5 \mathrm{~cm}$. in five patients with mitral regurgitation, and $1.5 \mathrm{~cm}$. or less in 9 cases of stenosis or stenosis with regurgitation.

Mitral opening snaps were present in every patient except one, and occurred 0.04 to 0.11 seconds after aortic valve closure. 


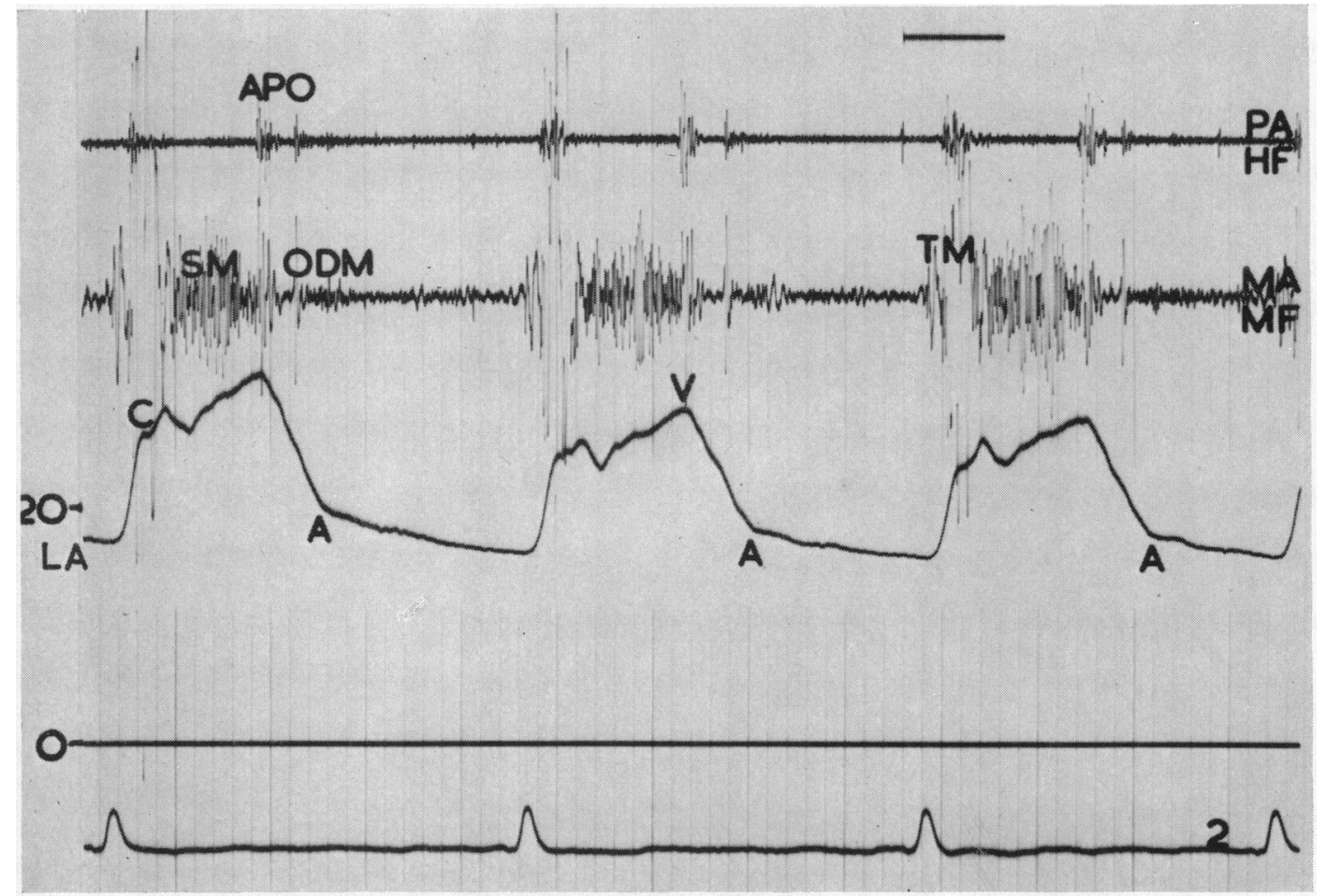

FIG. 6.-Mitral stenosis with regurgitation. Pulmonary area high frequency (PA/HF) and mitral area medium frequency (MA/MF) phonocardiograms, left atrial pulse (LA) and lead 2 electrocardiogram.

$\mathrm{APO}=$ aortic and pulmonary valve closure and mitral opening snap vibrations.

$\mathrm{ODM}=$ mitral opening snap followed immediately by a diastolic murmur of quiet onset.

$\mathrm{TM}=$ tricuspid and mitral valve closure.

The left atrial pulse shows "c" and "v" waves and the downslope from " $v$ " is angulated at the annular ascent point (A).

Diastolic Murmurs. In mitral regurgitation the diastolic murmur began loudly at the time of the third heart sound and annular ascent point and faded away as left atrial and ventricular pressures equalized (Fig. 1-3). Murmur vibrations were absent or of small size between the opening snap and the annular ascent point. In cases of stenosis or stenosis with regurgitation diastolic murmur vibrations began quietly soon after the left atrial " $\mathrm{v}$ " peak at a point where the opening snap is recorded if it is present (Fig. 4-7).

Third heart sounds were present in the majority of heart cycles in patients with mitral regurgitation, and absent in those with stenosis or stenosis with regurgitation (Fig. 1-7). Third sounds occurred $0 \cdot 1$ to $0 \cdot 17$ seconds after aortic valve closure and were generally loudest at the beginning of an expiratory pause. In every case the interval between aortic valve closure and the third sound equalled the interval between aortic valve closure and the annular ascent point when averaged over ten beats.

The left atrial annular ascent point could be distinguished in every patient 0.1 to 0.17 seconds after aortic valve closure (Fig. 1-6).

The nadir of left ventricular diastolic pressure was recorded satisfactorily in seven patients $0 \cdot 16$ to 0.25 seconds after aortic valve closure. The nadir always occurred after the annular ascent point. Simultaneous left atrial and ventricular pressure pulses illustrating this feature have been published by Braunwald et al. (1955), McKusick (1958), Luisada and Liu (1959), and Bernstein et al. (1960). 


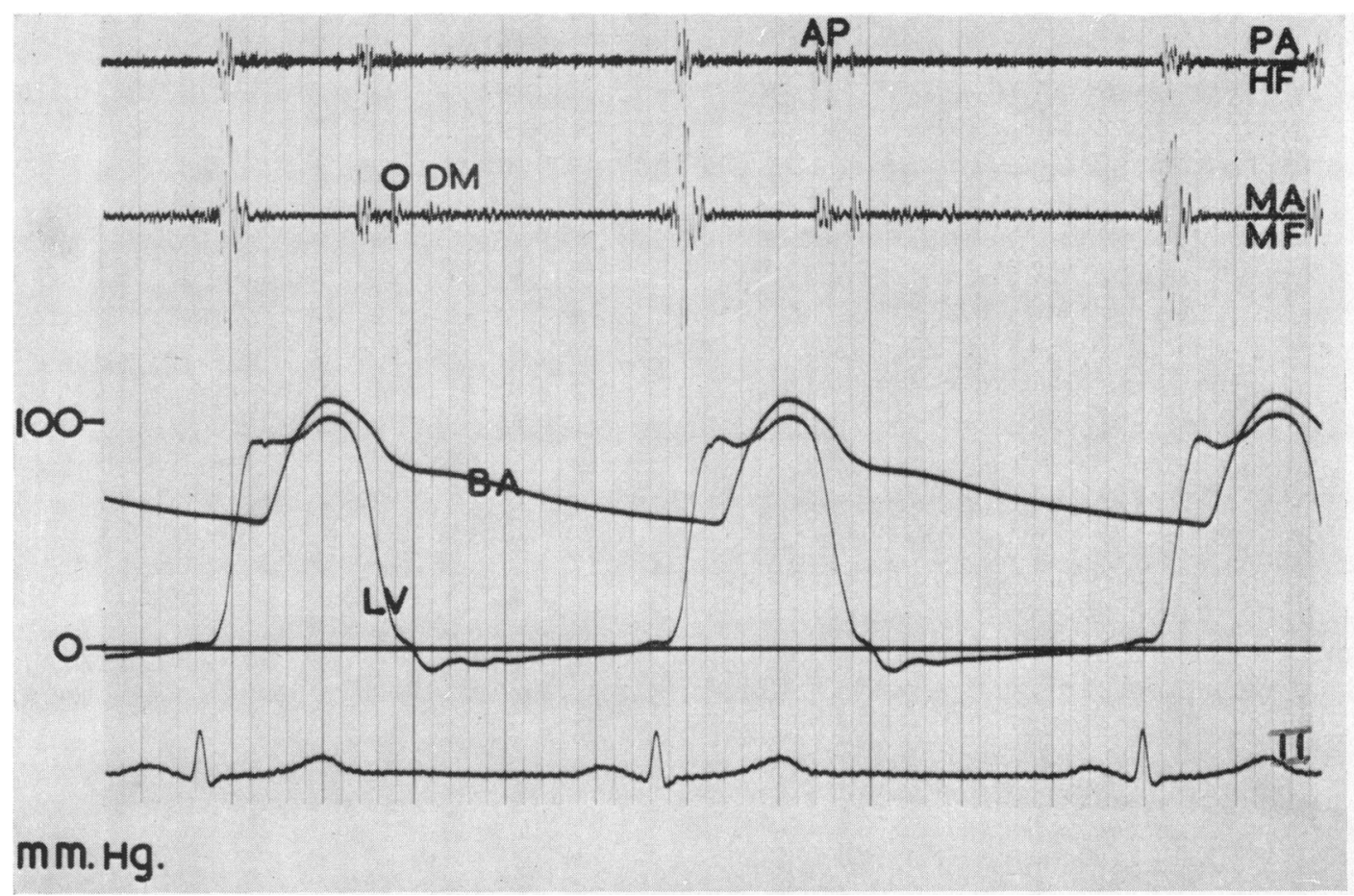

Fig. 7.-Mitral stenosis. Pulmonary area high frequency (PA/HF) and mitral area medium frequency (MA/MF) phonocardiograms, brachial arterial (BA) and left ventricular (LV) pulses and lead 2 electrocardiogram (II).

The mitral diastolic rumble (DM) has a quiet beginning at the opening snap $(O)$ and shows presystolic accentuation.

$\mathrm{AP}=$ aortic and pulmonary valve closure. $\mathrm{O}=$ mitral/opening snap.

Left atrial stasis waves began $0 \cdot 21$ to 0.7 (average 0.31 ) seconds after aortic valve closure when diastasis was present in cases of mitral incompetence (Fig. 1-3). The beginning of the stasis wave marks the point of equalization of left atrial and ventricular pressures. In severe mitral obstruction with or without regurgitation the pressures cannot equalize and stasis waves cannot occur.

Left ventricular end-diastolic pressure lay between -4 and $+2 \mathrm{~mm}$. $\mathrm{Hg}$ in five patients with stenosis with regurgitation, and between +7 and $+16 \mathrm{~mm}$. $\mathrm{Hg}$ in ten patients with predominant regurgitation (Fig. 7 and 8).

Left atrial "v" peak pressures are not reported except to mention that in severe mitral valve disease the range of values obtained is similar in stenosis and regurgitation, and in cases with and without third heart sounds.

\section{Discussion}

The origin of the third heart sound in mitral regurgitation has been debated since Thayer drew attention to the sign in 1909. Differences of opinion as to its cause have generally stemmed from failure to agree upon its exact relationship in time to events in the cardiac cycle. By defining the point at which the third sound occurs in the left heart cycle, the present study offers a standard against which theories of causation can be tested.

\section{The Relation of the Third Sound to Left Heart Events in Mitral Regurgitation}

In mitral incompetence the third sound coincides with the annular ascent point (Fig. 1-3), a feature of the left atrial pulse which Radner (1957) has observed in health and mitral stenosis. 
Since the annular ascent point occurs at the same interval after aortic valve closure in mitral incompetence as in mitral stenosis, and may be followed by an annular ascent wing in either case, it is likely that it represents the same event in both conditions. Radner contends that the left atrial pressure changes occurring at the annular ascent point are caused by ascent of the mitral annulus fibrosus and consequent reduction of the mitral orifice. This explanation is supported by an examination of the diastolic murmur in mitral regurgitation.

In patients with severe mitral obstruction the diastolic murmur begins quietly at the opening snap (Hultgren and Leo, 1959; Nixon et al., 1960). The present study confirms the opinion that in predominant mitral incompetence the diastolic murmur begins with the third heart sound (Carey Coombs, 1924; Hultgren and Leo, 1959), or with vibrations so large as to be indistinguishable from a third heart sound in many cycles (McKee, 1938; Taquini et al., 1940; Hultgren and Leo, 1959; Nixon et al., 1959, 1960). Murmur vibrations are absent or small in the period of fast atrial decompression between the opening snap and third heart sound. (The contradictory observation by Hubbard et al. (1959) may stem from the high proportion of cases without opening snaps in their series.) It is reasonable to explain the late onset of the diastolic murmur of mitral regurgitation by postulating the development of obstruction at the mitral valve at the time of the annular ascent point and third heart sound due to a movement of the mitral curtains in the direction of closure. Since the mural cusp is usually rigid and immobile in chronic rheumatic mitral regurgitation a diastolic murmur may signify mobility in the aortic cusp, as does the presence of an opening snap (Nixon et al., 1959, 1960). This suggestion is supported by the observations of Brigden and Leatham (1953) who found severe disease of both cusps when cases with an opening snap and a diastolic murmur were rejected from a study of mitral incompetence. Their assumption that a diastolic murmur excludes "pure" mitral regurgitation is not supported by the surgical findings in patients from the present series.

Evidence for the sudden development of mitral obstruction at the time of the third heart sound, before the ventricle has ceased to relax, is also seen in the left atrial pressure pulse in mitral incompetence. At the annular ascent point the " $y$ " descent of left atrial pressure suddenly decelerates or even rises in the annular ascent wing. It is easier to believe that this is caused by sudden partial or total closure of the mitral orifice than by a reflected wave from a ventricle which is still expanding as it receives its load. Henderson and Johnson (1912) drew attention to the way in which rapid flow from atrium to ventricle can close the atrio-ventricular valve, and Little (1951) showed that the normal mitral valve may close at the end of the rapid inflow period.

Physiological and pathological third heart sounds have been related to events in the cardiac cycle by many techniques, and apparent contraditions have resulted from the use of different reference tracings. The third sound was related to the end of the first third of diastole by Warren et al. (1958), and to the last moment of the ventricular inflow phase by Braun-Menendez and Orias (1934). Most workers have recorded the sound during the period of ventricular filling and not at its end (Thayer, 1909; Robinson, 1908; Lewis and Dock, 1938; Frost, 1949; Little, 1951 ; Kuo et al., 1951 ; Dock et al., 1955; Hultgren and Leo, 1959). Kuo et al. (1957) showed that the third heart sound occurs before equalization of left atrial and ventricular pressures. None of the recorded observations appear inconsistent with the view that the third sound in mitral regurgitation occurs when the mitral cusps and chordæ are tensed by ascent of the annulus as the ventricle continues to fill. Lewis (1934), Lewis and Dock (1938), Brady and Taubmann (1954) and Dock et al. (1955) have emphasized the momentary reversal of outward movement of the apical impulse in patients with third heart sounds. This brief inflection of the apex occurs while the lateral wall of the ventricle is still expanding, and is probably caused by traction on the papillary muscles during sudden annular ascent. The inflection may indicate that the mitral cusps and chordæ are taut from ventricular distension before the annulus ascends.

The Relationship of the Physiological to the Pathological Third Heart Sound

Most authors agree that the pathological third heart sound is an exaggeration of the physiological 
third heart sound (Barié, 1893; Thayer, 1909; Battro et al., 1934; Cossio, 1938; Lewis and Dock, 1938; Frost, 1949; Leatham, 1951; Dock et al., 1955; McKusick, 1958; Harvey, 1958), for each occurs about the same time after aortic valve closure (Thayer, 1909; Mannheimer, 1942; Rappaport and Sprague, 1942; Frost, 1949; Leatham 1951). Moreover pathological and physiological third heart sounds have a similar sound frequency (Frost, 1949; Esch et al., 1957; Jacono and Friedland, 1959), and similar relationships to a momentary reversal of left ventricular apical expansion (Brady and Taubmann, 1950) and to a rightward and headward force demonstrated by the ballistocardiograph (Dock et al., 1955). The coincidence of the annular ascent point with the physiological third sound (Radner, 1957, 1958) and with the pathological third sound of mitral regurgitation, shown in this study, adds further support to the theory of their common origin.

It is relevant to consider whether the third sound marks a normal event occurring in every heart cycle, or whether it is caused in health and disease by special conditions which are present at some times and not at others. Third sounds are audible in the majority of normal young people (Obrastzow, 1905; Bridgman, 1915; McKee, 1938; Cossio, 1938; Orias and Braun-Menendez, 1939; Taquini et al., 1940; Rappaport and Sprague, 1942; Mannheimer, 1942; Evans, 1943; Frost, 1949; Sloan et al., 1952), and the vibrations can usually be recorded in health when they are too quiet to be heard with the stethoscope (McKee, 1938; Braun-Menendez, 1938; Mannheimer, 1942; Rappaport and Sprague, 1942; Sloan et al., 1952). Therefore it seems likely that a normal event in the cardiac cycle occurs at the time of annular ascent causing vibrations which may be inaudible, audible in health as the physiological third heart sound, or audible in disease as the pathological third sound. The origin of these vibrations is disputed.

\section{The Origin of the Third Heart Sound}

The noise may arise from a high rate of blood flow across the mitral valve, from tension in the heart muscle, or from tautening of the mitral cusps and chordæ.

High Rate of Blood Flow across the Mitral Valve. The third sound is a "transient," not a long drawn out series of vibrations, and it is therefore unlikely to arise from continuous flow through the mitral valve. It does not begin with the onset of atrio-ventricular flow, nor does it occur when flow is greatest. The third sound may be prominent in patients with a low cardiac output from hypertensive or ischæmic heart disease, it may still be present when blood flow into the heart is stopped (Smith, 1944), and it is rare in thyrotoxicosis (Frost, 1949) where there is a high rate of flow.

Tension in the Heart Muscle. Potain (1900) considered that "the dilating ventricle quickly reaches a point where the fibrous resistance of its wall limits its distension, and the latter, sharply arrested, causes a tension, a shock, and the gallop sound." (Translated by Dock et al., 1955). This view is tenable if ventricular muscle tenses like a sheet in the wind in cases with third heart sounds, if the third sound occurs at the moment of tension, and if heart muscle is capable of producing sound under the action of physiological force. In the patients investigated here third sounds occurred during the period of ventricular relaxation and not at or after the nadir of left ventricular diastolic pressure. Dock (1959) showed from apical records, border motion studies, animal experiments and from fluoroscopy in Valsalva's manœuvre that in life the ventricle does not tauten like a blown-up paper bag, but is capable of distending far beyond the size at which third sounds occur. He also demonstrated that the forces required to evoke audible sounds from ventricular muscle are greatly in excess of those present in living animals. The association of a third sound with a diseased ventricle is not in any way proof of its origin in vibrating muscle.

Tautening of the Mitral Cusps and Chordae. It is likely that the origin of the third heart sound lies in sudden tautening of the mitral cusps and chordæ. The forces required to produce sound from these tissues are within physiological limits (Dock, 1959). An origin in suddenly tensed fibrous tissue surrounded by sound-damping muscle is in keeping with the transient nature of the sound; so too is the occurrence of relatively high frequency vibrations (McKusick, 1958; Esch et al., 1959), and occasional extreme loudness (Conner, 1927). This theory of origin is supported by the present observation that the third sound coincides with ascent of the annulus, an event which is capable of 
producing sudden tension in the mitral cusps and chordæ. It is further supported by the observation that the diastolic murmur and sudden deceleration in " $y$ " descent occur at the time of the third sound in severe mitral regurgitation, and indicate the sudden onset of a degree of mitral obstruction. Smith's (1944) observation that the third sound persisted, albeit very quietly, in the dog when the heart was empty or when the leaflets were prevented from approximating, provided that the heart was beating vigorously, is not inconsistent with the theory that sudden ascent of the annulus can so tense the chordæ as to produce a faint sound. It does suggest that the third sound is caused by an event of the vigorously beating heart regardless of the conditions of blood flow and ventricular filling.

The earliest observers of the third heart sound in health and in mitral regurgitation (Gibson, 1907; Hirschfelder, 1907; Thayer, 1909) attributed it to forceful early diastolic closure of the mitral valve. These authors emphasized the achievement of rapid ventricular filling in their cases, using as evidence the late diastolic jugular pulse wave rising from the nadir of " $y$ " descent to the inscription of the "a" wave. The sign was described by Mackenzie in 1902. The relationship between the left atrial form of this stasis wave and the third sound of mitral incompetence has been examined by Nixon and Wooler $(1960,1961)$. The valvular origin of the third sound has been asserted repeatedly by Dock (Lewis and Dock, 1938; Dock et al., 1955; Dock, 1949 and 1959). The theory has given rise to new names for the third sound: "closing snap in diastole" (Hirschfelder, 1910) and "tension snap of the mitral valve" (Cossio, 1938).

Earlier theories about the origin of the third heart sound have been reviewed by Holt (1927) and Sloan (1958). Bramwell (1935) and Eddleman et al. (1954) suggested that the third heart sound and opening snap had a common origin in the opening of the atrioventricular valves. The two sounds have been recorded distinctly in one heart cycle too often for this view to be maintained (Fig. 1-3). Einthoven (1907) thought that the third heart sound might be caused by vibration of the semilunar valves. Since these valves are firmly closed at the time of the third sound this explanation is unlikely to be true. The theory that the third heart sound is caused by impact of the heart against the chest wall is disproved by those observers who have heard or recorded this sound from the exposed heart (Sloan, 1958).

\section{The Loudness of the Third Sound in Heart Disease}

The balance of evidence favours the view that the normal and pathological third heart sound is caused by sudden tautening of the mitral cusps and chordæ. The reason why the intensity of the sound should range from inaudible vibrations to transients louder than the first and second sounds may lie in changes in the valves and chordæ, in the ventricle, or in the rate of ventricular filling. Dock (1959), and Hultgren and Leo (1959) have pointed out that the valves and chordae thicken with age and disease, and when thickened, are more productive of noise.

An audible third heart sound is an important feature of mitral regurgitation, hypertensive and ischæmic heart disease, and cardiomyopathy. In mitral incompetence there is an abnormally high flow of blood across the mitral valve-the forward flow plus the regurgitant flow-but in the other diseases blood flow is frequently reduced. However, elevation of left ventricular end-diastolic pressure is common to all. Selzer's (1959) records of elevated left atrial pressure reflect left ventricular diastolic hypertension in ischæmic and hypertensive heart disease. In the present series of cases of severe mitral incompetence left ventricular end-diastolic pressures ranged from 7 to $16 \mathrm{~mm}$. $\mathrm{Hg}$, agreeing with the observations of Ross et al. (1958). In mitral incompetence the third heart sound occurs with a mitral orifice measuring $2.0 \mathrm{~cm}$. or more, and left ventricular diastolic hypertension may be diagnosed from the left atrial stasis wave which is present in diastasis (Nixon and Wooler, 1961) (Fig. 8).

The pathological third sound has been said to result from absolute ventricular diastolic overloading (an excessive load of blood) or from relative ventricular diastolic overloading (an injured myocardium with a normal load of blood) (McKusick, 1958). Both states are associated with left ventricular diastolic hypertension. Many clinicians have related the occurrence or intensification of 


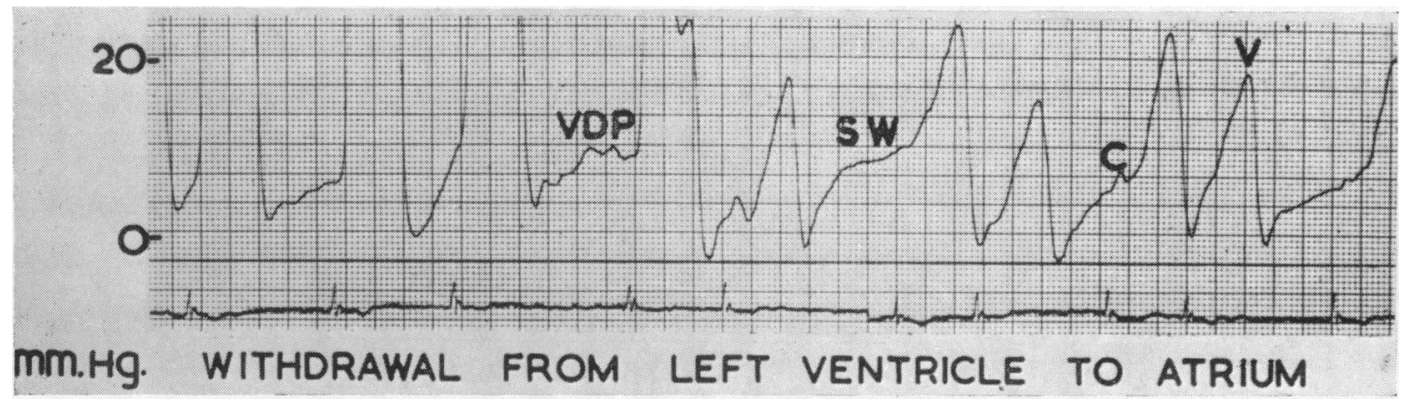

FIG. 8.-Mitral regurgitation. Pressure recorded as the tip of the catheter was withdrawn from left ventricle to left atrium, with lead 2 electrocardiogram. Ventricular diastolic pressure (VDP) rises quickly, and is similar to the left atrial stasis wave (SW) in late diastole.

$\mathrm{C}$ and $\mathrm{V}=$ left atrial "c" and " $\mathrm{v}$ " waves (paper speed $=25 \mathrm{~mm} . / \mathrm{sec}$.).

the pathological third sound to worsening of the heart's condition, and a reduction or disappearance of the sound to improvement. (Lewis and Dock, 1938; McKee, 1938; Evans, 1943; Frost, 1949; Harvey, 1958). These observations are consistent with the sound's waxing and waning as left ventricular diastolic pressure rises and falls during the development and recovery from heart failure, and are the reverse of those which would be expected if increased blood flow was responsible for gallop rhythm. Mond and Oppenheimer (1929) agreed that elevated ventricular diastolic pressure, which may appear before other signs of heart failure, is the main condition necessary for the establishment of gallop rhythm. Evans (1943) suggested that in pathological triple rhythm ventricular pressure does not fall below the threshold at which a third sound appears. Jhaveri et al. (1960) found good prognosis in cases of mitral incompetence without third heart sounds, and it is likely that the disease in their cases was too slight to cause elevation of left ventricular diastolic pressure.

Since the time of Gibson (1907) and Thayer (1909) it has been known that the third sound may be reduced in intensity by manœuvres which decrease the volume or pressure of the venous return to the heart, and vice versa. (Boyer, 1942; Evans, 1943; Smith, 1944; Sloan and Wishart, 1953 (a) and (b)). It seems just as likely that these act by altering diastolic tension within the ventricle as by changing the rate of blood flow through the heart. The physiological third heart sound (Thayer, 1909) and the third sound of mitral incompetence grow louder with the first slow beats of expiration. The cause of this may be transient elevation of left ventricular diastolic pressure when blood flow from the lungs is greatest.

Since the pathological third heart sound can occur without high flow in the presence of left ventricular diastolic hypertension, and since the high flow conditions responsible for protodiastolic gallop rhythm may well act by raising left ventricular diastolic pressure, it is not easy to prove or disprove the theory that a high rate of flow through the heart can cause a pathological third heart sound. Perhaps the rarity of protodiastolic gallop in thyrotoxicosis without cardiac enlargement is an apposite observation (Frost, 1949), and it is to be expected that gallop rhythm will occur in this condition when heart failure supervenes (Evans, 1943).

If ventricular distension increases the distance from the apex of the ventricle to the annulus fibrosus without lengthening the fibrous parts of the valve it must, after a point, increase tension in the mitral cusps and chordæ. This increase in tension is probably responsible for third sound vibrations reaching audible loudness under conditions of left ventricular diastolic hypertension. The reason for third sound vibrations reaching audible loudness in the young is a matter for speculation; perhaps left ventricular residual volume is relatively great in the youthful heart.

Mitral Stenosis. From time to time it is suggested that a third heart sound may occur in cases of severe mitral stenosis. This has not been the author's experience. The explanation may be that the gallop sound has come from the failing right ventricle or that an opening snap has been wrongly labelled. In trivial mitral stenosis obstruction at the mitral valve may be so slight as to permit rapid 
left ventricular filling and stasis (Morrow et al., 1957). In this situation it might be possible for thickened cusps and chordæ to make audible the third heart sound vibrations of a vigorously beating heart, particularly if aortic valvular disease, hypertension or myocardial disease were also present. In mitral stenosis it is common for diastolic murmur vibrations to increase in amplitude at the time of the third heart sound, and this may be caused by ascent of the annulus and narrowing of the mitral lumen.

\section{SUMMARY}

In mitral regurgitation and in health the third heart sound coincides with ascent of the mitral annulus fibrosus. This event is marked in the left atrial pressure pulse by sudden deceleration of " $y$ " descent or by the start of a transient positive wave, the annular ascent wing. It is marked phonocardiographically by the onset of the diastolic murmur of mitral regurgitation. These pressure and sound phenomena are attributed to apposition of the mitral curtains caused by ascent of the annulus fibrosus and abrupt elongation of the ventricle; sudden tensing of the mitral valves and chordæ is considered responsible for third heart sound vibrations. The loudness of the third sound in heart disease is related to stiffening of the fibrous part of the valve which renders it capable of producing more sound, and to diastolic distension of the left ventricle which presumably acts by increasing tension in the valve cusps and chordæ. It is considered unlikely that this third sound can be caused by vibrations in the relaxing and sound-deadening heart muscle.

I am deeply indebted to Mr. G. H. Wooler and Professor R. E. Tunbridge for making this work possible. Mr. R. Addyman, Staff-Nurse E. Kirkbridge and Mrs. J. Blake are to be thanked for zealous assistance.

Through the kindness of Dr. A. G. Morrow, Director of Surgery at the National Heart Institute, I was able to learn the transeptal method of left heart catheterization from Dr. J. Ross, Jr., and Dr. E. Braunwald. I wish to thank Dr. J. R. H. Towers, Dr. W. Whitaker, and Mr. J. A. Aylwin for referring patients for diagnostic investigations.

The Board of Governors of the United Leeds Hospitals, the Trustees of the Nuffield Foundation, the Medical Research Council and private benefactors have generously provided funds for equipment and technical assistance.

\section{REFERENCES}

Barié, E. (1893). Sem. médicale, 13, 473. (Quoted by Dock, Grandell, and Taubman, 1955).

Battro, A., Braun-Menendez, E., and Orias, O. (1934). Rev. argent. Cardiol., 1, 117.

Bernstein, W. H., Fierer, E. M., Laszlo, M. H., Samet, P., and Litwak, R. S. (1960). Brit. Heart J., $22,37$.

Boyer, N. H. (1942). Amer. Heart J., 23, 797.

Brady, J. P., and Taubman, F. (1950). Amer. Heart J., 39, 834.

Bramwell, C. (1935). Quart. J. Med., 4, 149.

Braun-Menendez, E. (1938). Lancet, $2,761$.

Br., and Orias, O. (1934). Rev. argent. Cardiol., 1, 101.

Braunwald, E., Moscovitz, H. L., Amram, S. S., Lasser, R. P., Sapin, S. O., Himmelstein, A., Ravitch, M. M., and Gordon, A. J. (1955). Circulation, 12, 69.

Brigden, W., and Leatham, A. (1953). Brit. Heart J., 15, 55.

Bridgman, E. W. (1915). Heart, 6, 41.

Conner, L. A. (1927). Amer. Heart J., 11, 514.

Coombs, C. F. (1924). Rheumatic Heart Disease. John Wright \& Sons, Bristol.

Cossio, P. (1938). Rev. argent. Cardiol., 4, 301 and 383.

Dock, W. (1949). New Engl. J. Med., 241, 767.

- (1959). Circulation, 19, 376.

— Grandell, F., and Taubman, F. (1955). Amer. Heart J., 50, 449.

Eddleman, E. E., Willis, K., Walker, P. P., Christianson, L., and Pierce, J. R. (1954). Amer. J. Med., $17,15$.

Einthoven, W. (1907). Pflüg. Arch. ges. Physiol., 120, 31.

Esch, I., Heeger, H., and Saiko, G. (1957). Z. Kreislforsch., 46, 917. Abstracted in (1958) Circulation, $18,299$.

Evans, W. (1943). Brit. Heart J., 5, 205.

Frost, J. (1949). Acta med. scand., 133, 268. (1949). Acta med. scand., 134, 153.

Gibson, A. G. (1907). Lancet, 2, 1380.

Harvey, W. P. (1958). Circulation, 18, 1017.

Henderson, Y. (1906). Amer. J. Physiol., 16, 325.

Henderson, and Johnson, F. E. (1912). Heart, 4, 69.

Hirschfelder, A. D. (1907). Johns Hopk. Hosp. Bull., 18, 265.

(1910). Diseases of the Heart and Aorta. J. B. Lippincott and Co., Philadelphia and London. 
Holt, E. (1927). Amer. Heart J., 2, 453.

Hubbard, T. F., Dunn, F. L., and Neis, D. D. (1959). Amer. Heart J., 57, 223.

Hultgren, H., and Leo, T. (1959). Medicine, Baltimore, 38, 103.

Jacono, A., and Friedland, C. (1959). Amer. J. Cardiol., 4, 207.

Jhaveri, S., Czoniczer, G., Reider, R. B., and Massell, B. F. (1960). Circulation, 22, 39.

Kuo, P. T., Hildreth, E. A., and Kay, C. F. (1951). Ann. intern. Med., 35, 1306. Schnabel, T. G., Blakemore, W. S., and Whereat, A. F. (1957). J. clin. Invest., 36, 1035.

Leatham, A. (1951). Lond. Hosp. Gaz., No. 4 Clin. Supp. (1952). Brit. med. Bull., 8, 334.

Lewis, J. K. (1934). Arch. intern. Med., 53, 741.

, and Dock, W. (1938). J. Amer. med. Ass., 110, 271.

Little, R. C. (1951). Amer. J. Physiol., 166, 289.

Luisada, A., and Liu, C. K. (1959). Cardiology, Vol. 3., Part 7. McGraw Hill Book Company Inc., New York, p. 110.

McKee, M. H. (1938). Amer. Heart J., 16, 79.

Mackenzie, J. (1902). The Study of the Pulse. Young J. Pentland, Edinburgh and London.

McKusick, V. A. (1958). Cardiovascular Sound in Health and Disease. The Williams and Wilkins Company, Baltimore.

Mannheimer, E. (1942). Acta med. scand., 111, 442.

Mond, H., and Oppenheimer, E. (1929). Arch. intern. Med., 43, 166.

Morrow, A. G., Braunwald, E., Haller, J. A., and Sharp, E. H. (1957). Circulation, 16. 399.

Nixon, P. G. F. (1960). Thorax, 15, 225.

, and Wooler, G. H. (1960). Brit. med. J., 2, 1122.

-, - (1961). Brit. Heart J., 23, 161.

- - _ and Radigan, L. R. (1959). Circulation, 19, 839.

,,$---(1960)$. Brit. Heart J., 22, 395.

Obrastzow, W. P. (1905). Z. klin. Med., 57, 70.

Orias, O. (1949). New. Engl. J. Med., 241, 763.

, and Braun-Menendez, E. (1939). The Heart Sounds in Normal and Pathological Conditions. Oxford University Press, London.

Potain, P. C. E. (1900). Sem. médicale, 20, 175.

Radner, S. (1957). Acta med. scand., 159, 219.

(1958). Proceedings of the Harvey Tercentenary Congress. Blackwell Scientific Publications, Oxford.

Rappaport, M. B., and Sprague, H. B. (1942). Amer. Heart J., 23, 591.

Robinson, G. C. (1908). Amer. J. Med., 135, 670.

Ross, J., Jr. (1959). Surg. Forum., 9, 297.

, Braunwald, E., and Morrow, A. G. (1958). Amer. J. Cardiol., 1, 11.

Selzer, A. (1959). Circulation, 20, 243.

Sloan, A. W. (1958). Medicine, Baltimore, 37, 197.

-, Campbell, F. W., and Henderson, A. S. (1952). Brit. med. J., 2, 853.

二, and Wishart, M. (1953a). Brit. Heart J., 15, 25.

- - (1953b). J. Physiol., 122, 135.

Smith, J. R. (1944). Amer. Heart J., 28, 661.

Taquini, A. C., Massell, B. F., and Walsh, B. J. (1940). Amer. Heart J., 20, 295.

Thayer, W. A.' (1909). Arch. intern. Med., 4, 297.

Warren, J. V., Leonard, J. J., and Weissler, A. M. (1958). Ann. intern. Med., 48, 580.

Wiggers, C. J. (1921). Amer. J. Physiol., 56, 415 and 439. 